\title{
Complexos Metálicos na terapêutica do Cancro
}

\section{Introdução}

\subsection{Complexos metálicos em medicina}

Os elementos inorgânicos e em particular os metais, apesar de constituírem menos de $1 \%$ dos átomos dos organismos vivos, são essenciais à vida, pela sua participação em numerosos processos bioquímicos vitais. No entanto, muitos metais são tóxicos e mesmo aqueles que são essenciais tornam-se tóxicos quando em excesso. ${ }^{\text {la }}$ Durante muito tempo os cientistas mostraram pouco interesse no desenvolvimento de aplicações terapêuticas de complexos metálicos, devido em parte ao conhecimento da sua toxicidade, agravada pela existência de numerosos casos de envenenamentos, especialmente com metais pesados. $^{1 \text { a }}$

Apesar do conhecimento, desde há longa data, das propriedades terapêuticas de alguns metais, o reconhecimento da sua eficiência farmacológica foi um processo lento. Apenas no início do século XX surgiram os primeiros medicamentos contendo metais: o salvarsan (1910), um medicamento de arsénio particularmente eficiente no tratamento da sífilis e os medicamentos contendo mercúrio, novasural (1910) e saligran (1924), usados como agentes diuréti$\cos ^{2}$ Apesar destes medicamentos terem sido posteriormente substituidos por compostos orgânicos, existem actualmente numerosos medicamentos inorgânicos com um papel específico e relevante no tratamento de algumas doenças. Por exemplo, a auranofina (fi-

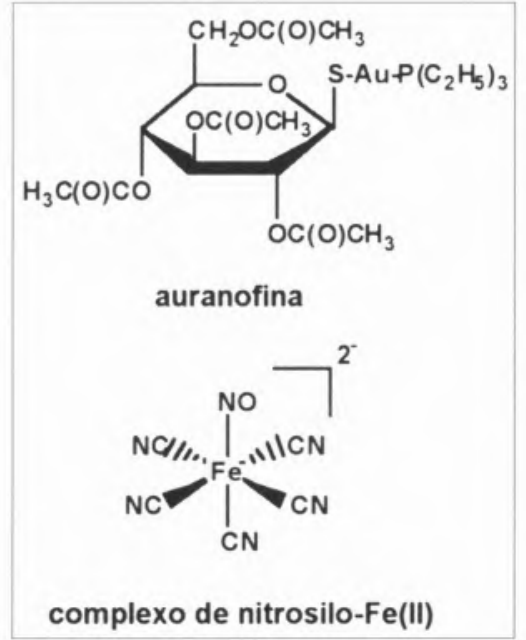

Figura 1 Exemplos de medicamentos contendo metais

gura 1) é utilizada no tratamento da poliartrite crónica; ${ }^{3}$ o complexo de nitrosilo-Fe(II) (figura 1) é utilizado como um medicamento de emergência em crises de elevada tensão arterial; os sais de lítio são usados em psiquiatria para tratamento da depressão; o bismuto é utilizado no tratamento de úlceras e muitas preparações de zinco e ferro são utilizadas para aplicações em dermatologia. ${ }^{3,4}$

Finalmente, a descoberta da actividade anti-tumoral da cisplatina há cerca de 30 anos atrás, ${ }^{5}$ provou ser possivel encontrar novos complexos metálicos com propriedades terapêuticas excelentes e constituiu um grande incentivo para o desenvolvimento e procura de novos complexos metálicos com actividade semelhante. Nos últimos 25 anos, os medicamentos de platina nomeadamente a cisplatina e a carboplatina, trouxeram um beneficio terapêutico significativo no tratamento do cancro. O desenvolvimento de novos complexos de platina tem continuado, numa tentativa de meIhorar as características de resistência e toxicidade da cisplatina. Actualmente, cerca de 10 novos complexos deste metal contendo as estruturas mais variadas, encontram-se em diferentes fases de avaliação clínica. ${ }^{6}$ Paralelamente ao desenvolvimento dos complexos de platina assistiu-se à exploração da actividade anti-tumoral de outros metais, com o objectivo de alargar o espectro de acção terapêutico da cisplatina. Têm sido preparados e testados numerosos complexos metálicos, muitos dos quais apresentam características que poderão ser úteis na terapêutica do cancro e dos quais se destacam os complexos organometálicos de ciclopentadienilo, o budotitânio e os complexos de ruténio. ${ }^{2}$

Um dos principais objectivos a ter em conta na procura de um novo medicamento anti-tumoral, diz respeito à sua selectividade no ataque às células do carcinoma. Neste contexto, tem-se assistido ao desenvolvimento de complexos metálicos com actividade citostática, direccionados exclusivamente para as células tumorais. Esta especificidade é conseguida através da ligação dos agentes metálicos a biomoléculas transportadoras com uma afinidade específica para as células tumorais.

Adicionalmente, alguns metais possuem isótopos radioactivos e esta propriedade tem sido explorada em medicina nu- 
clear que estuda a utilização in vivo de compostos contendo átomos radioactivos. A emissão de radiação $\gamma$ ou $\beta$ por parte de alguns metais, localizados nas células tumorais, permite a sua utilização no diagnóstico e terapêutica do cancro, respectivamente. ${ }^{7}$

\subsection{O Cancro; desenvolvimento e avaliação de novos medicamentos}

Desde o início do século XX até aos dias de hoje tem-se assistido no mundo ocidental, a um aumento progressivo da mortalidade causada pelo cancro, que da sétima posição passou a ocupar a segunda. Números mais altos só são ultrapassados pelas doenças do coração e sistema circulatório. ${ }^{2}$

O cancro não é uma única doença, mas várias. As células tumorais caracterizam-se por um crescimento invasivo e descontrolado, causado pela desregulação dos processos bioquímicos normais, originando um novo tecido designado por neoplásico. ${ }^{\text {ta }}$ Se o cancro é descoberto a tempo, a cirurgia e a radioterapia, poderão ser suficientes para o seu tratamento mas os estágios mais avançados da doença requerem a quimioterapia.

Num esforço de desenvolvimento de novas terapias para o cancro é fundamental um melhor entendimento da doença, dos seus processos celulares e biologia tumoral. Estes conhecimentos deverão acompanhar a procura de novas soluções de terapia. No entanto, esta interacção tem sido normalmente um acontecimento posterior ao processo de descoberta e o desenvolvimento de novos compostos anti-tumorais está ainda dependente de muito trabalho preparativo, sujeito ao estabelecimento de relações empiricas estrutura-actividade e sujeito às deficiências dos métodos de avaliação. ${ }^{1 a}$

As relaçōes estrutura/actividade de um agente citostático são extremamente complexas e até hoje, não se encontrou nenhuma relação que possa ser generalizada. Isto não é surpreendente se considerarmos os numerosos factores que podem influenciar a actividade de um medicamento, como sejam as reacçōes que se podem dar antes da entrada na célula, a velocidade e mecanismo de entrada na célula, a velocidade de ligação ao DNA, o tipo e proporção dos aductos formados e a probabilidade de reparação destes aductos. ${ }^{8}$ Todos estes factores têm o potencial de afectar profundamente a actividade citostática. Adicionalmente, para um mesmo medicamento, o mecanismo de resposta pode variar drásticamente, dependendo do tipo de tumor. ${ }^{8}$

\subsection{Mecanismo de acção dos complexos metálicos}

A reactividade química particular dos complexos metálicos oferece oportunidades de interacção biológica, como a participaçẫo em reacções redox ou a substituição de ligandos por moléculas biológicas. A previsão do sucesso terapêutico de um novo complexo metálico será orientada pelo conhecimento da sua química particular e dos seus "alvos" moleculares. ${ }^{9 a}$

A química particular ou reactividade de um determinado complexo metálico é determinada pelo estado de oxidação do metal e pelos seus ligandos fixos e lábeis. A activação de um complexo metálico poderá requerer a substituiçäo de um ou mais ligandos lábeis por água, que será facilmente substituída por uma biomolécula nucleofilica, por exemplo, um nucleótido ou um aminoácido contendo enxofre, e assim causar uma lesão biológica. Os ligandos fixos influenciam o alvo molecular e a reactividade do metal, através das suas interacçōes com o meio fisiológico. Por exemplo, a possibilidade de um complexo entrar num ambiente hidrofóbico como as membranas, aproximar-se de biomoléculas carregadas como o DNA ou encaixar-se num receptor de uma proteina, pode ser programada pela natureza destes ligandos..$^{9:}$

Sobre os "alvos"moleculares conhece-se ainda muito pouco. A natureza e propagação dos efeitos iniciados pela coordenação de um metal a certas biomoléculas permanece um mistério. O DNA é considerado o alvo mais provável da acção anti-tumoral dos metais, mas não deve ser excluida a possibilidade de existirem outros alvos, concretamente a membrana celular. Esta contém "antenas celulares" para comunicação intercelular e serve como "ponto de ancoragem" para adesão intra e extracelular de moléculas. Pensa-se que estas duas funçōes possam estar relacionadas com o mecanismo de crescimento tumoral e metástase. ${ }^{9 a}$

Existem evidências experimentais para a existência de mecanismos de transporte que levam os metais do plasma sanguíneo às moléculas-alvo: as propriedades de ligação de um substrato são controladas por gradientes naturais que existem nos diferentes compartimentos celulares (p.e., pH, ATP ou gradientes iónicos). Estes gradientes poderão também alterar as afinidades relativas dos metais para as diferentes moléculas ou compartimentos celulares, facilitando a ligação do metal ao seu centro activo. ${ }^{2}$

\section{Complexos de Platina com Actividade anti-tumoral}

\subsection{Descoberta e desenvolvimento da cisplatina}

A cis-diaminodicloroplatina(II) (cisplatina) (figura 2) foi o primeiro complexo metálico a ser utilizado na terapêutica do cancro. Foi descoberto em 1844 por Michele Peyrone, ${ }^{9 b}$ mas só um século mais parte se descobriria, acidentalmente, a sua actividade anti-tumoral. Em 1969, Barnett Rosenberg examinou a influência de um campo eléctrico no crescimento de bactérias, usando eléctrodos de platina submergidos numa solução contendo cloreto de alumínio. ${ }^{9 t}$ Nestas condições experimentais formase o complexo cis-diaminotetracloroplatina(IV) (Pt(NH3)2Cl4). Rosenberg observou o crescimento das bactérias em cerca de 300 vezes o seu comprimento, sem no entanto observar divisão celular. A influência selectiva na divisão celular, juntamente com o crescimento desregulado, levou Rosenberg a pensar que os complexos de platina poderiam ser capazes de inibir o crescimento de tumores. Intuitivavemente Rosenberg decidiu sintetizar alguns complexos de amino-platina muito simples, como a cisplatina (figura 2) e testou-os em mo- 
delos tumorais experimentais, observando uma redução do tamanho do tumor e um prolongamento do tempo de vida do animal doente.

Apesar de algumas reservas iniciais em relação aos metais pesados, os compostos de cisplatina entraram rapidamente em estudos clínicos, mostrando efeitos inibitórios excelentes em tumores em estado avançado. A cisplatina constitui nos dias de hoje, um dos três medicamentos mais usados mundialmente na quimioterapia do cancro, sendo efectiva no tratamento de vários tipos de cancro particularmente os cancros genitais, com taxas de sucesso entre 70 a $90 \%$, e no cancro da bexiga, cabeça e pescoço. ${ }^{10}$

Infelizmente, apesar desta excelente actividade anti-tumoral, existem vários as-

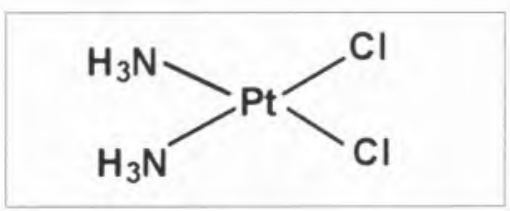

figura 2 CISPLATINA: cis-

diaminodicloroplatina(II)

pectos negativos associados ao uso da cisplatina, nomeadamente a existência de efeitos secundários que incluem náuseas, vómitos, neuropatia, supressão mielóide, ototoxicidade e mais significativamente a toxicidade nos rins, que constitui o efeito secundário mais grave e limitativo da dose adiministrada. ${ }^{10} \mathrm{Um}$ outro aspecto negativo diz respeito à resistência: ao fim de 4 a 6 ciclos de tratamento, os tumores inicialmente sensiveis ao medicamento, tornam-se resistentes. Nestes casos uma terapia subsequente com outros agentes antitumorais revela-se geralmente ineficiente e o doente acaba por morrer. ${ }^{9 b}$ Hoje sabe-se que os factores associados à resistência da cisplatina estão relacionados com uma diminuição do transporte celular, um aumento da desintoxicação via elevaçăo dos níveis da glutationa, um aumento da reparação dos aductos platina/DNA e um aumento da tolerência celular aos aductos cisplatina/DNA. ${ }^{11}$

\subsection{Mecanismo de acção da}

\section{cisplatina}

Os efeitos citostáticos da cisplatina parecem estar relacionados com a formação de aductos estáveis com o DNA que bloqueiam ou inibem a transcrição, afectando o crescimento do tumor, ${ }^{12}$ sendo o aducto mais frequente o que estabelece a ligação entre duas deoxiguanosinas vizinhas de uma mesma cadeia. Não é fácil compreender a especificidade da acção da cisplatina para as células tumorais quando, com base no mecanismo sugerido, seria de esperar uma inibição geral dos tecidos em proliferação. A investigação terá ainda que evoluir no sentido de um melhor entendimento das interacções da cisplatina com o DNA e outras biomoléculas, com o objectivo de explicar o seu mecanismo de acçāo, responsável pela sua especificidade para certos tumores. A descoberta recente da interacção entre a cisplatina e os processos de sinalização celular e da sua capacidade de iniciar a apoptose nalgumas células tumorais, sāo observaçōes interessantes, cujo significado ainda terá que ser integrado no conhecimento actual. Estes dois fenómenos indicam a possibilidade de existirem novos centros de interacçăo com a célula tumoral. ${ }^{13 a}$

\subsection{Sintese de derivados directos da cisplatina}

Apesar do inquestionável sucesso da cisplatina na quimioterapia do cancro, tornava-se urgente melhorar a sua eficiência clínica em termos da resistência e redução da toxicidade. Na etapa seguinte do desenvolvimento dos complexos de platina, pretendia-se a identificação de um derivado que mantivesse a actividade anti-tumoral da cisplatina, mas reduzisse os seus efeitos tóxicos. ${ }^{10}$ Foram sintetizados milhares de novos complexos com estrutura semelhante à cisplatina e cerca de mil foram sujeitos a testes pré-clínicos. Destes, apenas um a carboplatina (figura 3) foi aprovada para uso clínico, ${ }^{1 \bar{a}}$ apresentando uma menor toxicidade gastrointestinal e uma ausência de toxicidade nos rins. 0 efeito secundário limitativo da dose administrada consiste na supressão mielóide. ${ }^{13 a}$
Na etapa seguinte do "design" de novos complexos de platina, evoluíu-se no sentido de se alterar a estrutura base $\mathrm{e}^{14}$ por modificação da natureza ou número dos ligandos fixos, com o objectivo principal de se ultrapassar o problema da resistência. Desta investigação surgiu uma classe principal de complexos, designada por complexos de terceira geração, baseada no ligando 1,2-diaminociclohexano. Por exemplo, a oxaliplatina (figura 4) foi aprovada para uso clínico em França, onde é utilizada em quimioterapia combinada, para tratamento do cancro nos pulmões, ovário e cólonrecto 15 e a loboplatina (figura 4 ) encontra-se actualmente em testes clínicos de fase II para o tratamento do cancro no ovário, pescoço, cabeça e pulmões. ${ }^{3}$

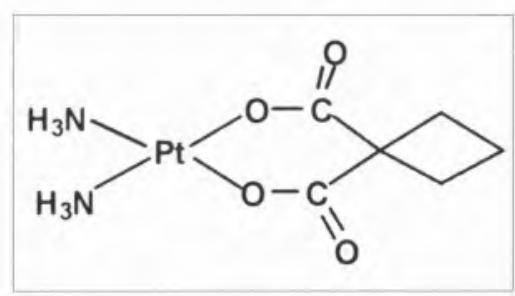

figura 3 carboplatina - cis.

diamino(ciclobutano-1,1.

dicarboxilato) platina(II).

\subsection{Complexos de platina contendo ligandos bioactivos}

A introdução de moléculas bioactivas nos ligandos dos complexos de platina constitui uma estratégia que permite 0 direccionamento da estrutura citotóxica para as células tumorais. Este conceito de "drug targeting" só poderá ser aplicado em tumores contendo receptores bioquímicos diferentes, em estrutura e quantidade, dos presentes nas células normais. Esta estratégia tem sido explorada por vários grupos mas até hoje o sucesso foi apenas moderado.

A utilização de liposomas como biomoléculas transportadoras do agente citostático, constitui a estratégia mais bem sucedida. Os liposomas são vesículos lipídicos biodegradáveis, não tóxicos, que podem alterar a distribuição do medicamento, por facilitarem o seu transporte através da bicamada lipídica das membranas celulares. ${ }^{8} 0$ complexo da figura 5 é um análogo da cisplatina com lipo- 


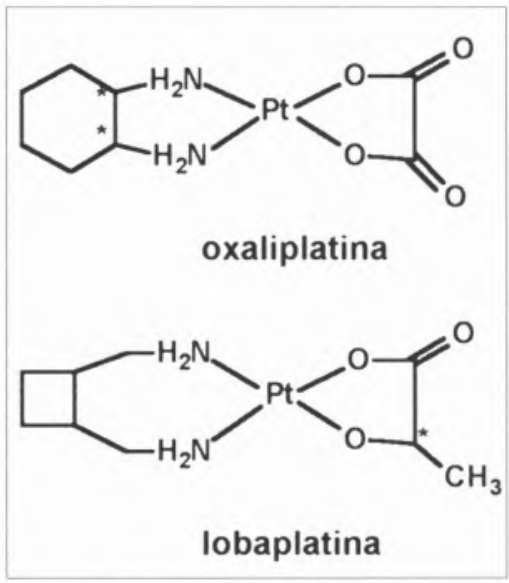

figura 4 Exemplos de complexos de platina de terceira geração

somas incorporados e revelou possuir uma excelente actividade contra metástases no figado e em modelos tumorais in vivo resistentes à cisplatina, encontrando-se actualmente em avaliação clínica. ${ }^{16}$

\subsection{Complexos dinucleares e trinucleares de platina}

Mais recentemente, têm sido desenvolvidos complexos di e trinucleares de platina. Espera-se que uma estrutura completamente diferente da estrutura clássica da cisplatina, possibilite a formação de diferentes aductos Pt/DNA, resultando num espectro clínico complementar à cisplatina.

No início de 1998, um novo complexo trinuclear de platina (figura 6) entrou em testes clínicos de fase I. ${ }^{13 \mathrm{t}}$ A sua estrutura é formada por duas unidades de [PtCl( $\left.\left(\mathrm{NH}_{3}\right)_{2}\right]$ ligadas por uma tetraamina não-covalente (figura 11). ${ }^{13 \mathrm{~b}} \mathrm{~A}$ carga global +4 aumenta a afinidade electroestática para o DNA e o complexo liga-se entre duas bases de cadeias diferentes distando em pelo menos 6 bases, com consequências graves a nivel da transcrição e replicação. A actividade deste complexo mostrou ser 100 vezes mais potente contra linhas celulares de tumores humanos, resistentes à cisplatina. $^{3}$

\section{Complexos Metálicos não contendo Platina}

Apesar de ser possível e evidentemente muito desejável que surjam novos compostos de platina capazes de resolver as limitações da cisplatina, tem-se assistido nas últimas duas décadas, ao desenvolvimento de outros complexos metálicos, que não contêm a platina.

Com a variação do metal e consequente alteração das suas propriedades químicas, será mais provável encontrar complexos metálicos com um espectro de acção terapêutico diferente dos compostos cisplatina. Com efeito tem-se verificado que o espectro de actividade, a toxicidade e o modo de acção dos novos metais testados, não se assemelha ao da platina.

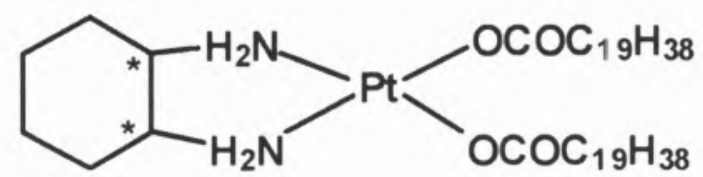

figura 6 Complexo trinuclear de platina

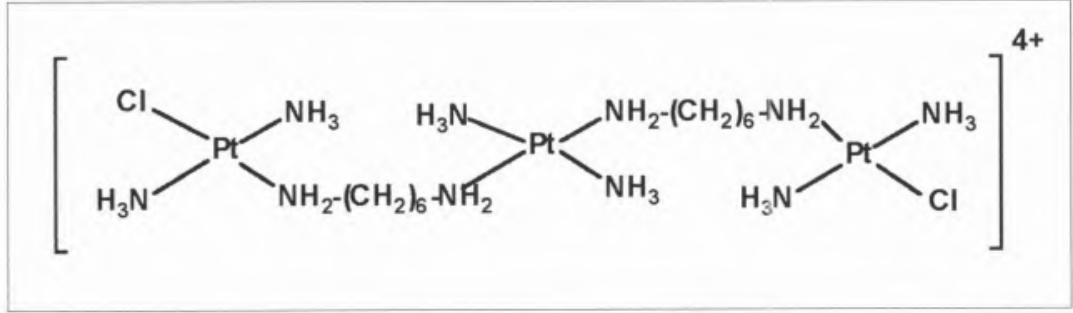

Têm sido sintetizados e testados muitos tipos de complexos metálicos que incluêm elementos do grupo principal como o estanho, gálio e germânio e elementos de transição, de localizações variadas, como o titânio, ruténio, vanádio, ferro, rénio, cobre, ouro, entre outros. ${ }^{9 c}$ Em seguida apresentam-se alguns exemplos de complexos metálicos que já atingiram algum sucesso na fase dos testes clínicos.

\subsection{Complexos metálicos de ciclopentadienilo}

\subsubsection{Metalocenos com actividade anti-tumoral}

Os metalocenos são compostos organometálicos de fórmula geral $\mathrm{X}_{2} \mathrm{MCp_{2 }}(\mathrm{Cp}$ $=\eta_{5}$-ciclopentadienilo e $X=$ halogéneo, carboxilato ou fenolato) apresentando uma geometria tetraédrica distorcida. Os seus ligandos orgânicos ciclopentadienilo são planares e formam entre si um ângulo diedro de cerca de $130^{\circ}$ e os dois ligandos $\mathrm{X}$ estão dispostos em posições adjacentes cis formando um ângulo de cerca de $80^{\circ}$ (figura 7). ${ }^{17}$

Em 1979, Köpf-Mayer e Köpf descobriram o primeiro metaloceno com actividade anti-tumoral, o dicloreto de titanoceno(IV). ${ }^{18}$ Logo em seguida foram preparados muitos outros metalocenos, $\operatorname{com} \mathrm{M}=\mathrm{V}, \mathrm{Nb}, \mathrm{Mo}, \mathrm{Ge}$, Sn e X = halogéneos, $N_{3}$ e NCS, para serem submetidos a testes de actividade anti-tumoral. ${ }^{\text {lc }}$

\subsubsection{Dicloreto de titanoceno $\left(\mathrm{Cl}_{2} \mathrm{TiCp}_{2}\right)$}

De todos os metalocenos sintetizados e testados $\circ \mathrm{Cl}_{2} \mathrm{TiCp}_{2}$ revelou ser o mais activo, tendo entrado em testes clínicos em 1991. $\mathrm{O} \mathrm{Cl}_{2} \mathrm{TiCp}_{2}$ é activo contra um variado espectro de carcinomas humanos, incluíndo o carcinoma gastrointestinal e da mama. ${ }^{19}$ Estes resultados são animadores tendo em vista que os tumores do estômago e do cólon são em geral insensíveis aos agentes citostáti$\cos$ comuns. ${ }^{20}$ Os seus efeitos tóxicos são manifestados no fígado e aparelho gastro-intestinal, mas são pouco severos e reversiveis. ${ }^{21} \mathrm{O} \mathrm{Cl}_{2} \mathrm{TiCp}_{2}$ encontra-se actualmente em testes clínicos de fase II com o objectivo de se determinar a tera- 


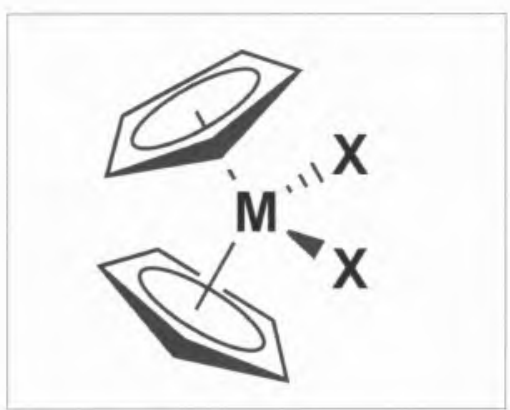

figura 7 Estrutura molecular dos complexos de metalocenos neutros $\left(\mathrm{C}_{2} \mathrm{H}_{5}\right)_{2} \mathrm{MX}_{2}$

pêutica mais adequada no tratamento de carcinomas humanos. ${ }^{1 b} \mathrm{~A}$ eficiência de $\mathrm{Cl}_{2} \mathrm{TiCp}_{2}$ face às celulas tumorais resistentes à platina, sugere um mecanismo de acção diferente. ${ }^{22}$ No entanto, ao contrário dos compostos de platina, conhece-se muito pouco sobre a química biológica dos compostos de titânio. ${ }^{19} \mathrm{Sa}$ dler e colaboradores ${ }^{23 a}$ propõem que o Ti(IV) seja transportado via transferrina do plasma sanguíneo para as células, onde, após ser libertado, estabelece a ligação aos fosfatos carregados negativamente ou aos átomos de azoto das bases do DNA. Outra proposta recente para o mecanismo de acção de $\mathrm{Cl}_{2} \mathrm{TiCp}_{2}$ sugere a inibição da actividade da proteína cinase $C$ ( $P K C)$, envolvida na regulação da proliferação celular e da topoisomerase II, responsável pelo bloqueio pré-mitótico. ${ }^{20}$

\subsection{Budotitânio}

A actividade anti-tumoral dos complexos metálicos da classe bis( $\beta$-dicetonato) foi descrita em 1982 por Keppler e colaboradores. ${ }^{24} 0$ complexo cis-dietoxibis(1-fenilbutano-1,3-dionato) de titânio(IV)) (budotitânio) (figura 8) foi o escolhido para ser desenvolvido e estudado clínicamente, tendo sido o primeiro complexo metálico com actividade anti-tumoral, não contendo platina, a ter entrado em testes clínicos em 1986.25

A actividade do budotitânio depende do ligando $\beta$-dicetonato, contendo um substituinte aromático planar, que se revela indispensável à sua actividade. Os ligandos nas posições cis têm pouca influência na reactividade do complexo, mas determinam as características de hidrólise do complexo e consequentemente a sua estabilidade. Os grupos etoxi foram os escolhidos, por possuírem uma menor velocidade de hidrólise, tornando o complexo suficientemente estável para uso clinico. ${ }^{24}$

Testes de actividade em modelos tumorais autóctones do cólon-recto, sugerem que o budotitânio possa ter uma aplicação clínica neste tumores. 0 budotitânio apresenta uma toxicidade reduzida em que os principais sintomas se revelam numa arritmía cardíaca e toxicidade nos rins, se bem que fraca e reversivel. ${ }^{9 d}$ Conhece-se pouco sobre o mecanismo de acção do butotitânio mas enquanto não surgem novos dados, pensa-se que esteja relacionado com o mecanismo de acção de $\mathrm{Cl}_{2} \mathrm{TiCp}_{2}$.

\subsection{Ruténio}

A reactividade do ruténio e as suas interacções químicas com os tecidos biológicos foram extensivamente estudadas por Clarke. ${ }^{23 b}$ Dos numerosos complexos de ruténio sintetizados e estudados, ${ }^{26,27}$ destacam-se os que possuem o ligando dimetilsulfóxido (DMSO) e ligandos heterocíclicos, como o complexo trans-[RuCl ${ }_{4}$ (DMSO) Im] Im (NAMI-A) (figura 9). Este complexo possui uma actividade particular no combate às metástases de tumores, tanto a nivel de prevenção como de tratamento. ${ }^{28}$

Ainda não se conhece o mecanismo de acção anti-metastático mas é de notar,

figura 8 (cis-dietoxibis(1-fenilbutano-1,3dionato) de titânio(IV)) (budotitânio)

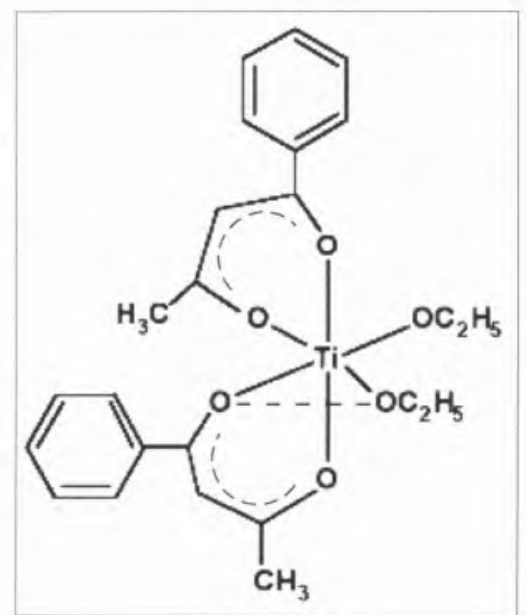

que apenas uma pequena fracção de NAMI-A atinge $o$ tecido tumoral e o efeito inibitório na redução da formação de metástases é observado mesmo usando doses muito baixas de ruténio, incapazes de induzir uma acção citostática directa no tumor primário. ${ }^{20}$ Num futuro próximo, espera-se que o desenvolvimento dos estudos clínicos a decorrer para NAMI-A permita a sua utilização na terapêutica em humanos, onde poderá desempenhar um papel muito importante no tratamento e prevenção de metástases.

\subsection{Gálio}

A actividade anti-tumoral do gálio foi observada em $1971^{9 e}$ e desde então, dois sais de gálio foram testados em doentes com cancro: o nitrato de gálio e o cloreto de gálio. 0 nitrato de gálio constitui 0 sal de gálio mais utilizado para efeitos terapêuticos sendo activo contra linfomas e tumores na bexiga. Em combinação com a vinblastina e ifosfamida, é utilizado no tratamento do carcinoma do uretélio e do carcinoma do ovário resistente à cisplatina. ${ }^{29}$ Os efeitos secundários do nitrato de gálio incluem uma arritmía cardíaca e toxicidade nos rins. ${ }^{20} \mathrm{O}$ interesse recente no cloreto de gálio de administração oral, está relacionado com o seu efeito sinérgico com a cisplatina no tratamento do cancro dos pulmões. ${ }^{30}$

$\mathrm{O} \mathrm{Ga}^{3+}$ é capaz de se ligar à transferrina, entrando nas células através dos seus receptores. ${ }^{3} \mathrm{~A}$ administração de gálio em doses terapêuticas na corrente sanguínea, resulta numa saturação de pelo menos $90 \%$ das transferrinas do soro, que passam a receber quantidades aproximadamente equivalentes de $\mathrm{Ga}^{3+}$ e $\mathrm{Fe}^{3+}$. Este excesso de gálio resulta numa redução da dose de ferro fornecida às células com a consequente quebra do nivel de hemoglobina e aumento dos receptores de transferrina nos linfócitos sanguíneos e nas células. As células tumorais, caracterizadas por um crescimento descontrolado e acelerado, apresentam um número mais elevado de receptores de transferrina e assim, o fornecimento de gálio é superior nas células tumorais. A actividade citostática do $\mathrm{Ga}^{3+}$ é indirecta e relacionada com a 


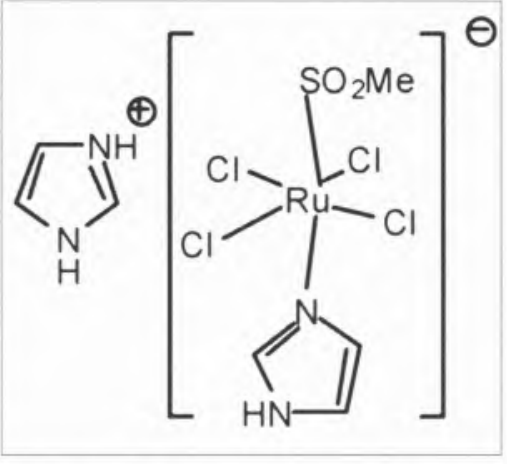

figura 9 trans. [RuCl4(DMSO) Im] Im (NAMI-A)

diminuição do fornecimento de ferro às células tumorais. ${ }^{20} \mathrm{~A}$ escassez do ferro e possivelmente a substituiçẫo directa do $\mathrm{Fe}^{3+}$ por $\mathrm{Ga}^{3+}$ no centro dinuclear na subunidade $R_{2}$ da reductase ribonucleótida, diminui a actividade desta enzima essencial, responsável pela conversão dos ribonucleótidos em desoxirribonucleótidos, antes da sua incorporação no DNA. Como resultado, as células são imobilizadas na fase $\mathrm{S}$ onde a reductase ribonucleótida é necessária para a síntese do DNA ${ }^{20}$

Dois isótopos de gálio, ${ }^{67} \mathrm{Ga} e{ }^{68} \mathrm{Ga}$, possuem propriedades radioactivas e $0^{57} \mathrm{Ga}$ tem sido explorado na técnica de diagnóstico da medicina nuclear, uma área terapêutica onde os metais têm desempenhado um papel fundamental e que se referirá brevemente.

\section{Medicina Nuclear}

A medicina nuclear estuda a utilização de materiais radioactivos para o diagonóstico e tratamento de doenças. ${ }^{7}$ Aproximadamente $2 / 3$ dos elementos da tabela periódica são elementos metálicos e muitos deles possuem radioisópos que poderão ser úteis em medicina nuclear. ${ }^{\text {lc }}$ Alguns destes radioisótopos como o ${ }^{67} \mathrm{Ga},{ }^{99} \mathrm{Tc},{ }^{111} \mathrm{In},{ }^{201} \mathrm{TI},{ }^{51} \mathrm{Co}$, e ${ }^{169} \mathrm{Yb}$ emitem radiações $\gamma$ de alta intensidade e com elevada penetração nos tecidos, sendo úteis para diagnóstico; outros, como o ${ }^{186} \mathrm{Re},{ }^{89} \mathrm{Sr}$ e ${ }^{153} \mathrm{Sm}$, emitem radiações $\beta$ que possuem intervalos de penetração mais curtos, sendo utilizados na terapêutica localizada de tecidos. ${ }^{3}$ Os radioisótopos podem ser administrados sob a forma de quelatos simples ou bifuncionais.
4.1. Aplicações de quelatos simples no diagnóstico de tumores

$\mathrm{O}^{67} \mathrm{Ga}$ é provavelmento o radiofármaco mais útil em oncologia, utilizado na detecção de alguns tumores como os linfomas, hepatomas, melanomas, carcinomas broncógenicos e doença de Hodgkins. ${ }^{\text {ge }}$ É administrado sob a forma de citrato que estabiliza a preparaçāo, impedindo a sua hidrólise. Após injecção, o gálio é rapidamente transquelatado para a transferrina que se liga aos respectivos receptores, abundantes nas células tumorais. Infelizmente, o gálio também se localiza em tecidos inflamados e em tecidos abdominais normais, o que impede o seu uso mais generalizado. Adicionalmente as propriedades físicas e biológicas do gálio não são as mais desejáveis, apresentando um tempo de vida relativamente longo e energias de fotâo que não sintonizam completamente com os sistemas de detecção mais comuns.

O ${ }^{99 m}$ tecnécio é inquestionavelmente o radioisótopo preferido na medicina nuclear devido às suas excelentes propriedades de diagnóstico, associadas à sua disponibilidade e baixo custo. Em associação com polifosfatos, em particular com o metileno difosfonato, forma quelatos estáveis que se localizam exclusivamente nos ossos o que permitiu que esta técnica se tornasse num dos testes diagonóstico mais úteis em medicina nuclear. ${ }^{\text {lc }}$

\subsection{Aplicações de quelatos bifuncionais}

Mais correntemente os agentes quelantes desempenham a dupla função de estabelecer uma associação estável a um radioisótopo e uma ligação covalente a uma molécula biológica. ${ }^{31}$

Um número considerável de biomoléculas tem sido identificado como possíveis agentes de radiomarcação. Por exemplo, os análogos da glucose exploram o aumento do metabolismo da glucose que se pensa existir nos tumores; os aminoácidos exploram o aumento da síntese proteica e os análogos da pirimidina interferem com a sintese do DNA. Estas moléculas têm sido habitualmente marcadas com radioisótopos de iodo, de carbono ou de flúor. 0 insucesso até agora observado na marcação destas pequenas moléculas com alguns radioisótopos metálicos, deve-se à presença do quelato, que sendo volumoso, inviabiliza a função biológica da molécula. ${ }^{1 e}$ No entanto os polipéptidos e proteínas, sendo moléculas relativamente grandes permitem a introdução do quelato, sem alteração da sua função biológica. A sua ligação a numerosos radioisótopos como ${ }^{99} \mathrm{mTc},{ }^{111} \mathrm{In},{ }^{90} \mathrm{Y},{ }^{188} \mathrm{Re}$ e ${ }^{186} \mathrm{Re}$ tem sido explorada, principalmente no desenvolvimento de anticorpos monoclonais. ${ }^{1 c}$

\subsection{Anticorpos monoclonais}

A descoberta da existência de antigenes associados às células tumorais levou à preparaçāo de anticorpos associados a espécies citostáticas (p.e. medicamentos, toxinas ou radioisótopos). ${ }^{33}$ Os anticorpos monoclonais são específicos para um único antigene, sendo produzidos em grandes quantidades e com um elevado grau de pureza.

Devido à elevada especificidade dos anticorpos para as células tumorais, esta técnica de diagnóstico poderia ser considerada uma terapêutica ideal. Infelizmente, até agora o seu sucesso foi apenas moderado, devido à presença de uma elevada actividade indesejável nos tecidos normais. Os anticorpos, sendo proteínas volumosas, encontram no organismo barreiras biológicas à sua difusāo. Adicionalmente, poderão ser com-

figura 10 Representação de um agente quelante bifuncional. ${ }^{32}$

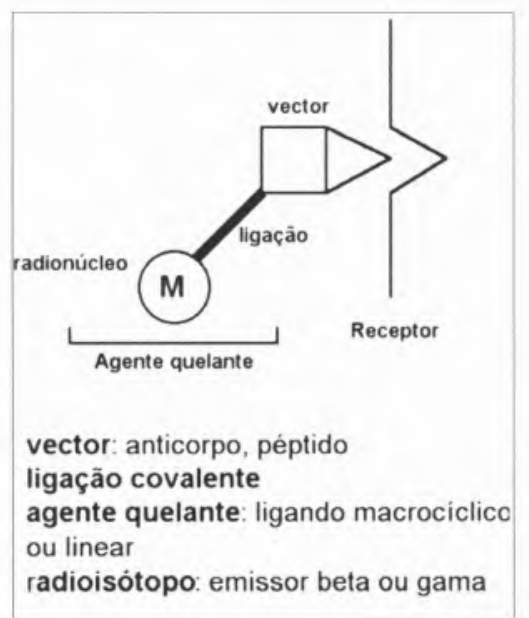


plexados no sangue por antigenes secretados pelo tumor ou por anticorpos produzidos pelo doente, em resposta aos próprios anticorpos marcados. Em ambos os casos estes imunocomplexos serão eliminados pelo aparelho urinário mas o processo é demasiado lento, o que constitui um "ruído de fundo" na detecção da radiação no tumor..$^{33} \mathrm{Ape}$ sar desta dificuldade, o número de anticorpos marcados submetidos a testes clínicos tem aumentado, e existem actualmente anticorpos monoclonais conjugados com radioisótopos de ${ }^{111} \mathrm{In}$, em utilização clínica no diagnóstico do cancro cólon-rectal e do ovário. ${ }^{3}$

\section{Terapia Fotodinâmica}

A terapia fotodinâmica envolve o tratamento de células e tecidos doentes com um composto fotossensibilizador e luz visivel. ${ }^{34}$ Esta técnica tem sido extensivamente explorada para o tratamento de tumores sólidos em humanos e já mostrou ser eficiente no tratamento de tumores na pele, pulmões, esófago e bexiga.35 A terapia fotodinâmica utiliza moléculas fotossensibilizadoras que são selectivamente retidas nas células cancerigenas e que após irradiação com luz visivel vermelha (> $650 \mathrm{~nm}$ ), onde a transparência dos tecidos é óptima, são capazes de gerar espécies citostáticas como o oxigénio singuleto, capaz de provocar lesões celulares. ${ }^{23 c}$

Os derivados hematoporfirínicos de estanho constituíram os primeiros compostos metálicos a serem utilizados na terapia fotodinâmica. A photofrin ${ }^{\oplus}$ foi aprovada para uso clínico em 1993 pelas autoridades canadianas. ${ }^{1 d}$ Estes agentes, constituem uma mistura de várias espécies de porfirinas que absorvem fracamente na região vermelha do visivel, do que resulta uma eficiência fotodinâmica fraca. Para além desta limitação, outras, como a insolubilidade em água e um tempo de eliminação do organismo muito lento, levaram ao desenvolvimento de compostos alternativos dos quais se destacam as texafirinas, ${ }^{3}$ fltalocianinas, ${ }^{36}$ purpurinas, ${ }^{37}$ entre outros.
A etiltiopurpurina de estanho(IV) (SnET2) (figura 11) constitui um fotossensibilizador muito potente que se encontra actualmente em avaliação clínica. É administrada sob a forma de uma emulsão ou incorporada em liposomas, ligando-se preferencialmente a lipoproteínas de elevada densidade existentes no plasma sanguíneo. A sua administração $(1 \mathrm{mg} / \mathrm{Kg})$ a ratos com tumores induzidos na bexiga, provocou, após 4 horas de tratamento, hemorragias, edemas e finalmente a necrose das células tumorais. $^{37}$

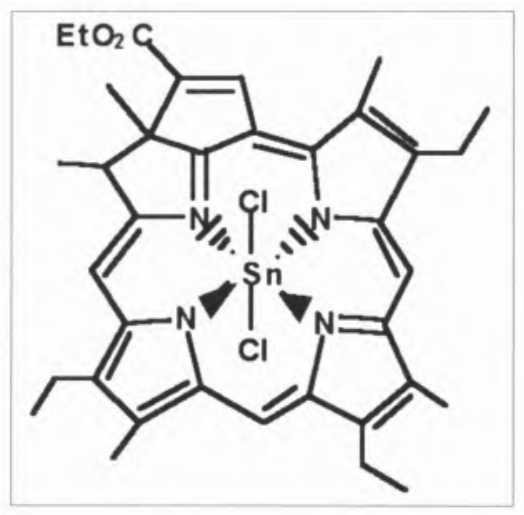

figura 11 etiltiopurpurina de estanho (SnET2)A)

\section{Conclusão}

Nos últimos 25 anos os medicamentos de platina (cisplatina e mais tarde a carboplatina) vieram trazer um desenvolvimento significativo na terapia do cancro, constituíndo sem dúvida o maior sucesso da quimioterapia inorgânica. No entanto, devido à sua toxicidade e resistência, o desenvolvimento de novos complexos de platina continua actual e este desenvolvimento deverá ser orientado na sintese de complexos estruturalmente diferentes da cisplatina, incluindo complexos di e trinucleares, que possibilitem novas interacções com o DNA, resultando num espectro de acção complementar à cisplatina.

O enorme sucesso da cisplatina originou um grande envolvimento entre a quími- ca inorgânica e organometálica, numa tentativa de descobrir novos compostos com actividade anti-tumoral. Infelizmente nenhum destes novos complexos atingiu o sucesso clínico da cisplatina, apesar de se terem descoberto complexos metálicos com propriedades específicas e importantes que se encontram actualmente em avaliação clínica.

O desenvolvimento nesta área deverá procurar uma interdisciplinaridade entre as áreas da química, biologia e medicina, como orientação no "design" de novos medicamentos. A necessidade desta colaboração foi já reconhecida na área dos compostos de titânio, no desenvolvimento do budotitânio, no reconhecimento de actividade anti-tumoral em compostos de ruténio, gálio, entre outros e na área de "drug targeting", com a preparação de complexos de platina contendo biomoléculas com afinidade para estruturas específicas dos tecidos tumorais.

Outras terapias do cancro, em que os metais têm desempenhado um papel fundamental incluem a terapia fotodinâmica e aplicações em medicina nuclear, que utiliza os radioisótopos de metais in vivo, para a detecção e terapêutica de tumores.

\section{Agradecimentos:}

Ao Professor Carlos Romão por todo o apoio prestado na elaboração desta monografia.

\section{Bibliografia}

1. Fricker, S. P. Ed. Metal Compounds in Cancer Therapy, Chapman\&Hall: London, 1994;

\section{a) Fricker, S. P.: Introduction;}

b) Köpf-Maier, P., Köpf, H.: Organometallic titanium, vanadium, niobium, molybdenum and rhenium complexes - early transition metal antitumor drugs;

c) Hnatowich, D. J.: The in vivo use of metallic radioisotopes in cancer detection and imaging; 
d) Crowe, A. J.: Antitumour activity of tin compounds;

2. Gielen, M. Ed. Tin-Based Antitumor drugs, Nato ASI Series: Springer-Verlag: Berlin, Heidelberg 1990;

3. Guo, Z., Sadler, P. J. Angew. Chem. Int. Ed. Engl. 1999, 38, 1512-1531;

4. Geoffrey, M. Beatty, W. K. The precious metals of medicine, Charles Scribner's Sons: New York, 1975;

5. Rosenberg, B. Van Camp, L, Trosko, J. E., Mansour, V. H. Nature 1969, 222, 385-386;

6. Köpf-Maier, P., Köpf, H. Chem. Rev. 1987, 87, 1137-1152;

7. Sadler, P. J., Clarke, M. J. Eds. Topics in Biological Inorganic Chemistry, Vol. 2, Springer-Verlag: Berlin, Heidelberg, 1999;

8. Hambley, T. W. Coord. Chem. Rev. 1997 166, 181-223;

9. Keppler, B. Ed. Metal complexes in cancer chemotherapy, VCH: Basel, 1993

a) Eggehard Holler: Mechanism of Action of tumor-inhibiting metal complexes;

b) Keppler, B. K.: Metal complexes in cancer chemotherapy;

c) Köpf-Maier, P.: Antitumor bis(cyclopentadienyl)metal complexes;

d) Keppler, B. K., Friesen, C., Vongerichten, H., Vogel, E.: Budotitane, a new tumor inhibiting titanium compound: Preclinal and clinical development;

e) Collery, P., Pechery, C.: Clinical experience with tumor-inhibiting gallium complexes;

10. Harrap, K. R., Cancer Tret. Rev. 1985 supl. A, 21-33;

11. Raynaud, F.I., Boxall, F. E., Goddard, P. M., Valenti, M., Jones, M., Murrer, B. A., Abrams, M., Kelland, L. R:, Clinic. Cancer Res. 1997, 3, 2063-2074;

12. Lippard, S. J., Sherman, S. E., Chem. Rev. 1987, 87, 1153-1181;
13. Nicholas P. Farrell, Ed. Uses of Inorganic Chemistry in Medicine, Royal Society of Chemistry: Cambridge, 1999

a) Petering, D. H., Xiao, J., Nyayapati, S., Fulmer, P., Antholine, W. E.: Oxidation damage by bloemycin, adriamycin and other cytotoxic agents that require iron or copper;

b) Farrell, N., Spinelli, S.: Dinuclear and trinuclear platinum anticancer agents:

14. Hollis, L. S., Amurdsen, A. R., Sterm, E. W. J. Med. Chem. 1989, 32, 128-136;

15. Uchida, N., Kasay, H., Takeda, Y., Maekawa, R., Sugita, K., Yoshioka, T. Anti-Cancer Res. 1998, 18, 247-252;

16. Brown, T., Al-Baker, S., Khokhar, A. R., Perez-Solder, R., J. Med. Chem. 1991, 34 , 325-329;

Köpf-Maier, P., Köpf, H. Chem. Rev. 1987, 87, 1137-1152;

18. Köpf, H., Köpf-Mayer, Angew. Int. Ed. Engl. 1979, 18, 477-478;

19. Yang, P., Guo, M., Coord. Chem. Rev. 1999, 189-211;

20. Clarke, J. M., Zhu, F., Frasca, D. R. Chem. Rev. 1999, 99, 2511-2533;

21. Köpf-Mayer, P. Köpf, H., Struct. Bonding 1988, 70, 103-181;

22. Moebus, V. J., Stein, R., Kieback, D. G., Runnebaum, I. B., Anticancer Res. 1997, 17, 815-821;

23. Clarke, M. J., Progress in Clinical Biochemistry and Medicine, Vol. 10, SpringerVerlag: Berlin, Heidelberg, 1989

a) Petra Köpf-Mayer: The Antitumor activity of transition and main-group metal cyclopentadienyl complexes;

b) Clarke, M. J.: Ruthenium chemistry pertaining to the design of anticancer agents;

c) Farrell, N.: Metal complexes as radiosensitizers;

24. Keppler, B. K., Heim, M. E. Drugs of the future 1988, 13, 637-652;
25. Keppler, B. K., Friesen, C., Moritz, H. G., Vongerichten, H., Vogel, E. Structure and Bonding 1991, 78, 97-127;

26. Clarke, M. J., Bitler, S., Rennert, D., Buchbinder, M., Kelman, A. D., J. Inorg. Biochem. 1980, 12, 79-87;

27. Keppler, B. K., Schmähl, D., Berger, M. R., Garzon, F. T. Cancer Chemother. Pharmacol. 1987, 19, 347-349;

28. Zorzet, S., lengo, E., Alessio, E., Bergamo, A., Coluccia, M., Boccarelli, A., Sava, G., J. Inorg. Biochem. 2000, 79, 173-177; 29. Dreicer, R., Propert, K. J., Roth, B. J., Einhorn, L. H., Loehrer, P. J. Cancer 1997. 79, 110-114;

30. Montreynaud, J. M. D., Etienne, J. C., Choisy, H., Pechery, C., Vallerand, H., Prevost, A., Perdu, D., Millart, H., Desoize, B., Morel, M., Collery, P. H. Anticancer Res.

$1991,11,1529-1532$;

31. Kaden, T. A. Chimia 2000, 45, 46-47;

32. Maumela, H., Hancock, R. D., Carlton, L., Reibenspies, J. H. J. Am. Chem. Soc.

1995, 117, 6698-6699;

33. Kenneth, A. F., Morgan, A. C., Monoclonal Antibody Therapy of Human Cancer, Martinus Nijhoff Publishing: Boston, 1985

34. Dolphin, D., Can. J. Chem. 1994, 72, 1005-1013;

35. Young, S. W., Woodburn, K. W., Wright, M., Mody, T. D., Fan, Q., Sessler, J. L., Dow, W. C., Miller, R. A. Photochem. and Photobiol. 1996, 63, 892-897;

36. Rosenthal, I., Ben-Hur, E. Int. J. Radiat. Biol. 1985, 47, 145-147;

37. Jori, G., Morgan, A. R., Garbo, G. M., Reddi, E., Polo, L., Cancer Lett. 1992, 217. 223;
"A molecule swims, dispersing its functionality, scattering its reactive centers. Not every collision, not every punctlious trajectory by which billiard-ball complexes arrive at their calculable meeting places leads to reaction. Most en- counters end in an harmless sidways swipe. An exchange of momentum, a mere deflection. And so it is for us."

Roald Hoffmann, "The Metamict state" (1987) 